\title{
Scaling Model of Low-Temperature Transport Properties for Molecular and Ionic Liquids
}

\author{
Vitaly B. Rogankov \\ Department of Physics and Materials Science, Odessa National Academy of Food Technologies, Kanatnaya Street 112, \\ Odessa 65039, Ukraine \\ Correspondence should be addressed to Vitaly B. Rogankov; vrogankov@yandex.ua
}

Received 23 September 2015; Accepted 10 November 2015

Academic Editor: Mohammad Al-Nimr

Copyright (C) 2015 Vitaly B. Rogankov. This is an open access article distributed under the Creative Commons Attribution License, which permits unrestricted use, distribution, and reproduction in any medium, provided the original work is properly cited.

\begin{abstract}
The universal scaling concept is applied to the low-temperature range of any liquid states and substances located between the melting $\left(T_{m}\right)$ and normal boiling $\left(T_{b}\right)$ points far away from the critical region. The physical reason to develop such approach is the revealed collapse of all low-temperature isotherms onto the single universal one argued by the model of fluctuational thermodynamics (FT) proposed recently by author. The pressure reduced by the molecular parameters of the effective short-range Lennard-Jones (LJ) potential depends here only on the reduced density. To demonstrate the extraordinary predictive abilities of the developed lowtemperature scaling model it has been applied to the prediction of equilibrium and transport (kinetic and dynamic viscosity, self-diffusion, and thermal conductivity) properties not only for molecular liquids but also for molten organic salts termed ionic liquids (ILs). The best argument in favor of the proposed methodology is the appropriate consistency with the scarce experiments prediction of transport coefficients for ILs on the base of universal scaling function constructed for the simplest LJ-like liquid argon. The only input data of any substance for prediction are the linear approximations of $T$-dependent density and isobaric heat capacity taken from the standard measurements at atmospheric pressure.
\end{abstract}

\section{Introduction}

The concept of scaling description at low temperatures based on the chosen effective form of a pair interparticle potential $\phi(r)$ is not completely novel. In particular, Hoover et al. [1] used the oversimplified (even in this specific region of a liquid state) so-called soft-sphere (ss) purely repulsive function

$$
\phi(r) \approx \varepsilon\left(\frac{\sigma}{r}\right)^{n}
$$

with constant ss-parameters $\varepsilon, \sigma$ and exponent $n$ ranging from about six $n \gtrsim 6$ for metals to about twelve for rare gases $n \lesssim 12$. Its limitative value $n \rightarrow \infty$ for a primitive hardsphere (hs) model leads the scaling variable $x$ introduced by the above authors $(\rho=N / V ; D=3)$,

$$
x=\left(\frac{\rho \sigma^{3}}{\sqrt{2}}\right)\left(\frac{\varepsilon}{k_{B} T}\right)^{D / n},
$$

to be only $\rho^{*}=\rho \sigma^{3}$-dependent. Another notable feature here is the implied PCS (principle of corresponding states) nature of such ss-scaling. Indeed one has to fix the exponent $n$ in (1) and (2) to select the group of similar substances.

Nevertheless the useful consequence of scaling transformation has been noticed by Hoover et al. [1] because any equilibrium or transport reduced properties (e.g., dynamic viscosity $\eta \rho^{-2 / 3}\left(m_{0} k_{B} T\right)^{-1 / 2}$ or self-diffusion $D \rho^{1 / 3}\left(m_{0} / k_{B} T\right)^{1 / 2}, m_{0}$ mass of particle) of different ss-systems with fixed exponent $n$ should coincide at the different $\rho$ and $T$ being expressed in terms of $x$-variable from (2). Of course, the additional serious restriction of ss-model (common with hs-model) is an absence of gas- (vapor-) liquid $(g, l)$ transition at any value of repulsive exponent.

It was shown recently $[2,3]$ in the framework of FTmodel [4-6] that the aforementioned oversimplifications of ss- and/or hs-model are not necessary if one considers the more realistic LJ-type potential $\phi_{l, n / m}$ with the effective $T$ dependent parameters $\sigma(T), \varepsilon(T)$ :

$$
\phi_{l, n / m}(r)=l \varepsilon(T)\left\{\left[\frac{\sigma(T)}{r}\right]^{n}-\left[\frac{\sigma(T)}{r}\right]^{m}\right\} .
$$




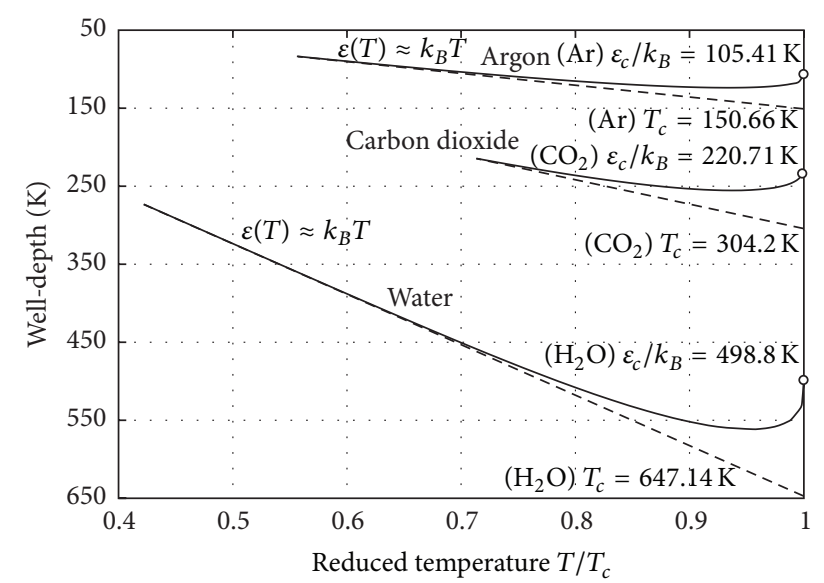

FIGURE 1: $T$-dependent well-depth of Lennard-Jones-type potential predicted by FT-model [3-6] on the base of experimental CXC-data for simple $(\mathrm{Ar})$, normal $\left(\mathrm{CO}_{2}\right)$, and polar $\left(\mathrm{H}_{2} \mathrm{O}\right)$ fluids; the lowtemperature range $\left[T_{m}, T_{b}\right]$ is specified by condition $T^{*} \approx 1$.

The advantage of such approach in comparison with the conventional estimates of their constant LJ-counterparts $\sigma$, $\varepsilon$ (mainly, from the experimental second-virial-coefficient's data) follows from the exact $T$-dependence derived by FTmodel for any subcritical temperature:

$$
\begin{gathered}
\varepsilon(T)=k_{B} T\left[1-Z_{l}(T)\right]=k_{B} T-\frac{P_{\sigma}(T)}{\rho_{l}(T)}, \\
\sigma^{3}(T)=\frac{3\left[A_{\sigma}(T)-2\right]}{4 \pi \rho_{d}(T)\left[A_{\sigma}(T)-1\right]}=\frac{3 b(T)}{2 \pi},
\end{gathered}
$$

where $Z_{l}=P_{\sigma}(T) /\left[\rho_{l}(T) k_{B} T\right]^{1 / 3}, A_{\sigma}(T)=\left(T / P_{\sigma}\right) d P_{\sigma} / d T$, $\rho_{d}=\left(\rho_{g}+\rho_{l}\right) / 2$, and $b(T)$ is the $T$-dependent parameter of excluded volume.

The determination of both is not trivial task for ILs [7] in which the vapor-pressure curve $P_{v}(T)$ is inaccessible by the standard lab. vacuum $\left(\sim 10^{-3}, \mathrm{~Pa}\right)$ experiment. However, just this restriction leads to the significant simplification of (4) at low temperatures $T \leq T_{b}$ as is shown in Figure 1 for the wellstudied simple and complex substances.

One may note that in parallel with the well-known condition for compressibility factor measured along the $g$ branch of CXC: $Z_{g}=P_{\sigma}(T) /\left[\rho_{g}(T) k_{B} T\right]=1$ its value $Z_{l}$ along the $l$-branch becomes here negligible or close to zero $Z_{l} \approx 0$. It leads to the interconsistent low-temperature values of LJ-parameters:

$$
\begin{aligned}
& T^{*}=\frac{k_{B} T}{\varepsilon} \approx 1, \\
& \rho^{*}=\rho \sigma_{0}^{3}=\left(\frac{3}{2 \pi}\right) \rho b_{0} .
\end{aligned}
$$

This is main assumption used in the present work to formulate the phenomenology of scaling transport coefficients and the respective equilibrium properties following from the generalized reduced form of LJ-EOS discussed below. It is interesting to compare the particular value of ss-scaling variable from (2) at hs-limit $n \rightarrow \infty: x_{\mathrm{hs}}=\rho \sigma^{3} / \sqrt{2}$ with that from LJ-model in (5b). For the former $T$ value is irrelevant while for the latter it determines by ( $5 \mathrm{a}$ ) the well-depth energy $\varepsilon$.

\section{Theoretical Basis of Global Asymmetry between the Nonordered (Gas) and Condensed (Liquid) States}

FT-model is described in detail elsewhere [2, 6]. For the convenience of readers its main concepts and results are discussed, in brief, below. In the field of equilibrium properties the essential feature is the well-founded rejection from the vdW-concept of a unified (i.e., common for both coexisting $g$ - and $l$-phases) EOS. This crucial step leads to the different alternative forms of local EOS for the above phases. They are based, however, on the same mathematical form accepted for an effective pair potential. The choice here of LJ-form requires, for information, at least, the superficial comparison of FT-model's results with the enormous number of simulated LJ-data described [8] just by the unified, purely empirical (so-called, fundamental) EOS for free energy. Despite the widespread belief of its universal applicability the arguments in favor of global indubitable asymmetry between $g$ - and l-states [2] are represented below in terms of respective local thermal EOSs. Another theoretical consequence of the discussed duality is the necessity to modify significantly the description of transport coefficients (see Section 3) without the permanent appeals to the well-established PCS formalism of a diluted nonordered $g$-phase and its properties $[9,10]$.

Striking asymmetry between the exact thermal EOSs of LJ-fluid may be easily revealed by the FT-model's approach. Thermal form of EOS $P(\rho, T)$ has the certain restrictions in the representation of caloric properties and, in particular, it needs the knowledge of so-called ideal gas heat capacities if the concept of a unified EOS is used. However, opposite to the conventional methodology of a fundamental (caloric) EOS, its exact form follows immediately for the given PCS-type of LJ-fluid $(l, n / m)$ (with the unspecified here integers) from the application of virial theorem [20]. One should note for that the evident formal property of underlying LJ-potential from (3). It is a sum of repulsive and attractive contributions with the different degrees of mathematical homogeneity ( $n$ and $m$ ). This observation leads straightforwardly to the equivalent forms of thermal EOS for a condensed LJ-fluid $(l, n / m)\left(P^{*}=\right.$ $\left.P \sigma^{3} / \varepsilon, Z=P^{*} / \rho^{*} T^{*}\right)$ :

$$
\begin{aligned}
P_{\mathrm{LJ}}^{*} & =\rho^{*} T^{*}+l\left(\frac{n}{D} \rho^{* n / D+1}-\frac{m}{D} \rho^{* m / D+1}\right), \\
Z_{\mathrm{LJ}}-1 & =\frac{l}{T^{*}}\left(\frac{n}{D} \rho^{* n / D}-\frac{m}{D} \rho^{* m / D}\right) .
\end{aligned}
$$

The important consequence of the latter is the irrelevant role of reduced $T^{*}$ along Boyle's line $Z=1$ (so-called Zeno-line) where the reduced density $\rho^{*}$ becomes constant in the whole range of $l$-states:

$$
\rho_{\mathrm{LJ}}^{*}=\left(\frac{m}{n}\right)_{Z=1}^{D /(n-m)}
$$


This result can be consistent with the known and empirically confirmed linearity of Zeno-line expressed, for example, in terms of dimensional variables for the vdW-EOS:

$$
\rho_{B}^{\mathrm{vdW}}=\frac{1}{b}\left(1-\frac{k_{B} b T}{a}\right)
$$

only if the reduced LJ-density $\rho_{\mathrm{LJ}}^{*}=\rho \sigma^{3}$ implies the inverse $\rho$-dependence of cubic LJ-diameter $\sigma^{3}(T)$ while the vdWcoefficient $a$ is linear in $T$.

At low temperatures where the specific conditions are accepted $T_{\mathrm{LJ}}^{*} \approx 1$ by (5a) and $\sigma_{\mathrm{LJ}}=\sigma_{0}$ by (5b) all LJ-isochores collapse to Boyle's line in accordance with (8). The scaling $P_{\mathrm{LJ}}^{*}\left(\rho^{*}\right)$-form of reduced pressure follows immediately from (7):

$$
P_{\mathrm{LJ}}^{*}\left(T_{\mathrm{LJ}}^{*} \approx 1\right)=\rho^{*}+l\left[\frac{n}{D} \rho^{* n / D+1}-\frac{m}{D} \rho^{* m / D+1}\right],
$$

which collapses here at $Z=1\left(P_{\mathrm{LJ}}^{*}=\rho_{\mathrm{LJ}}^{*}\right)$ to Boyle's line too. Such coincidence of isobars with isochores is a sign of singular incompressible behavior of liquid in the low-temperature region. It is noteworthy that Maslov [21, 22] has revealed recently the similar phenomenon in the low-temperature, so-called soft $L J$-fluid's states located below Zeno-line in the $(T, \rho)$-plane. He termed it "the jamming effect."

The described specific features of FT-model's LJ-liquid in the low-temperature region legalizes the simplest linear choice of input density data (Section 3) measured for any substances at atmospheric pressure $P_{0}$ and known even for ILs:

$$
\rho_{0}\left(T, P_{0}\right)=\rho_{0}^{0}\left(1-\frac{T}{T_{0}}\right),
$$

where "cold" density $\rho_{0}^{0}$ and "hot" temperature $T_{0}$ are the substance-dependent parameters (see, for comparison, vdWequality (9)). However, the two other input $T$-dependencies chosen below at fixed $P_{0}$ are less motivated and linear ones only for simplicity:

$$
\begin{gathered}
C_{P}^{0}\left(T, P_{0}\right)=C_{P_{0}}\left(1+\frac{T}{T_{P}}\right), \\
c_{s}^{0}\left(T, P_{0}\right)=C_{s_{0}}\left(1-\frac{T}{T_{s}}\right),
\end{gathered}
$$

where $C_{P}$ is the isobaric heat capacity of liquid (not that for ideal gas as it is in an unified EOS) and $c_{s}$ is the adiabatic speed of sound in a liquid too.

To be convinced of the global $(g, l)$-asymmetry $[2,3]$ existing for LJ-fluid one should consider the known virial expansion [23] for nonordered gas truncated after the second virial contribution $B(T) \rho$ :

$$
\begin{aligned}
& Z_{\mathrm{LJ}}^{g}-1 \approx \frac{2 \pi \rho^{*}}{3}\left[\left(\frac{l}{T^{*}}\right)^{D / n} \gamma\left(1-\frac{D}{n}\right)\right. \\
& \left.-\left(\frac{l}{T^{*}}\right)^{D / m} \gamma\left(1-\frac{D}{m}\right)\right] .
\end{aligned}
$$

Its comparison to (7) leads to the physically well-founded conclusion about the dominance of $\rho^{*}$ in $l$-phase but the dominance of inverse reduced temperature $l / T^{*}$ in $g$-phase. Moreover, at Boyle's condition $B\left(T_{B}\right)=0\left(Z_{\mathrm{LJ}}^{g}=1\right)$ the reduced density $\rho^{*}$ is irrelevant while the reduced temperature $T^{*}$ becomes constant:

$$
T_{\mathrm{LJ}}^{*}=l\left[\frac{\gamma(n, D)}{\gamma(m, D)}\right]^{m n / D(n-m)} .
$$

Such exact estimate can be quite useful at the development of non-mf (mean-field) LJ-theory [2] but in the present work has only passing interest.

\section{Continual Phenomenological Model of Transport Coefficients in the Low-Temperature Liquid}

The use of such standard notions [23], well-defined in the diluted $g$-phase as the statistical mean free-path of hs-particle between two collisions $\langle l\rangle$ and its mean transport velocity $\langle u\rangle$, becomes less informative due to the global $(g, l)$-asymmetry described in Section 2. It may be rejected in favor of the respective continual scales $\bar{l}$ and $\bar{u}$ for $l$-phase determined accurately by its thermodynamic equilibrium parameters $\rho$, $T$ ( $\bar{D}$ is the transport scale (ability) of continuum):

$$
\bar{D}=\bar{l} \bar{u}=\rho^{-1 / 3}\left(\frac{k_{B} T}{m_{0}}\right)^{1 / 2} .
$$

Hoover et al. [1] have restricted the proposed scaling ssdescription of transport coefficients only by the mechanical transport of mass and momentum by self-diffusion $D_{\text {sd }}$ and kinematic velocity $v=\eta / \rho m_{0}$ represented in terms of $x$ variable from (2):

$$
\begin{aligned}
\frac{D_{\mathrm{sd}}}{\bar{D}} & =D_{\mathrm{sd}}^{*}(x), \\
\frac{\nu}{\bar{D}} & \equiv \frac{\eta}{\left(\rho m_{0} \bar{D}\right)}=v^{*}(x) .
\end{aligned}
$$

It is natural to add here the temperature-conductivity $\chi=$ $\lambda /\left(\rho m_{0} C_{P}\right)$ expressed in terms of thermal conductivity:

$$
\frac{\chi}{\bar{D}} \equiv \frac{\lambda}{\left(\rho m_{0} C_{P} \bar{D}\right)}=\chi^{*}(x) \text {. }
$$

The certain similarity of scaling functions in (16b) and (17) with the known $[9,10]$ (inverse here) definitions of the Reynolds' $(\overline{\mathrm{Re}})$ and Pecle's $(\overline{\mathrm{Pe}})$ numbers for a convective flow can be noticed taking into account the choice of characteristic thermodynamic scales by (15).

There are two interconnected kinetic and field scales of velocity $\bar{u}$ and $c_{s}$ which both are necessary to reduce the momentum flux of pressure:

$$
\begin{aligned}
Z & =\frac{P}{\rho m_{0} \bar{u}^{2}}, \\
\overline{\mathrm{Eu}} & =\frac{P}{\rho m_{0} c_{s}^{2}}=P \beta_{s} .
\end{aligned}
$$


Former $Z$ is namely the compressibility factor discussed in Section 2 while the latter $\overline{\mathrm{Eu}}$ is the generalized Euler's number here ( $\beta_{s}$ is the adiabatic compressibility). One has to take into account that the spontaneously arisen in homogenous $(\rho, T)$ continuum local Gaussian (small and independent) fluctuations are diffusible with the speed of sound $c_{s}(\rho, T)$. Thus the transport process of any type depends simultaneously on two (molecular and wave) physical mechanisms [24].

To the best of my knowledge, the contribution of wave transport by the adiabatic fluctuations of pressure in the transport properties of liquids was ignored until now [21, 22]. Its physical nature is different from the molecularbased mechanism and based on the alternative concept of continuum. Hence, two independent scales of fast and slow transport should be taken into account for any fluctuationalrelaxation processes. Of course, it is hardly solvable problem to separate them and to determine accurately their relative contributions in the transport coefficients. In principle, they may be either comparable or essentially asymmetric (Section 5) for different liquids.

To make a start of consideration it was assumed below that the equal fractions of both contributions are appropriate for the thermal conductivity $\lambda$ and the dynamic viscosity $\eta$ :

$$
\begin{aligned}
& \lambda=\frac{\left(\lambda_{P}+\lambda_{s}\right)}{2}, \\
& \eta=\frac{\left(\eta_{P}+\eta_{s}\right)}{2},
\end{aligned}
$$

where subscripts of isobar $P$ and of isoentrop $s$ specify, respectively, the above types of transport. Then such concept of superposition was realized in the explicit phenomenological forms by the acceptance of two adjustable (but, presumably, universal for all substances) constant coefficients $A$ and $B$ :

$$
\begin{aligned}
\frac{\lambda}{C_{P}} & =\frac{x^{2 / 3}\left[m_{0} \varepsilon(T)\right]^{1 / 2}}{2 \sigma_{0}^{2}}\left[\chi^{*}(x)+\frac{A k_{B} c_{s}(T)}{m_{0} C_{P}(T) \bar{u}(T)}\right], \\
\eta & =\frac{x^{2 / 3}\left[m_{0} \varepsilon(T)\right]^{1 / 2}}{2 \sigma_{0}^{2}}\left\{\nu^{*}(x)+\exp \left[\frac{B c_{s}^{2}(T)}{\bar{u}^{2}(T)}\right]\right\} \\
\overline{\operatorname{Pr}} & =\frac{\eta C_{P}}{\lambda}=\frac{\nu^{*}(x)+\exp \left(B c_{s}^{2} / \bar{u}^{2}\right)}{\chi^{*}(x)+A k_{B} c_{s} /\left(m_{0} C_{P} \bar{u}\right)}
\end{aligned}
$$

where the generalized Prandtl's number $\overline{\operatorname{Pr}}$ here is essential to estimate the transport ability of a liquid, in total.

It is possibly the most remarkable consequence of the proposed correlations here that the universal coefficients $A=$ 2 and $B=0.0192$ for a variety of quite different, simple, and complex molecular and/or ionic compounds have been reasonably estimated, exclusively, from the tabular data [11] for the simplest LJ-like argon. Besides, here the chosen on the ad hoc basis correlations are based in (20)-(22) on the semiempirical PCS-functions recommended for a liquid state
$[9,10]$. The explicit purely empirical form of two scaling functions from (16a), (16b), and (17),

$$
\begin{aligned}
\chi^{*}(x) & =5(3 x-1), \\
v^{*} & =\frac{1.1}{1-(2 \pi / 3) x},
\end{aligned}
$$

is based exclusively on the argon's data [11] too. In other words, the main aim was the verification of the lowtemperature scaling concept but not the best fit of experimental data (see below) on the transport coefficients. More accurately, the above-supposed correlations (20)-(22) take a cue from their successful use in prediction of $\lambda(T)$ and $\eta(T)$, separately, within a group of thermodynamically similar substances. To go beyond the PCS-framework $[9,10]$ of molecular similarity, the more restrictive concept of scaling (which is applicable, supposedly, to the different PCS-groups) has been used. Hence, the reasonable agreement of the purely predictable coefficients below (Sections 4 and 5) (without any PCS-reference to values $\lambda^{0}$ and $\eta^{0}$ at fixed $T^{0}$ ) with the experimental data $\lambda(T), \eta(T)$ should bear testimony to general applicability of scaling methodology far away from a critical point. Thus, one may, of course, improve the chosen correlations (20)-(22) here, to fit better the universal scaling parameters $A, B$ within the possibly modified equations (23a) and (23b). However, the dual molecular-wave structure of all aforementioned universal functions should be the same. The generalized Mach number $(\overline{\mathrm{Ma}})$ following from the ratio of $Z / \overline{\mathrm{Eu}}$ in (18a) and (18b),

$$
\frac{1}{\overline{\mathrm{Ma}}}=\frac{c_{s}}{\bar{u}},
$$

is independent on the equilibrium parameters $P, \rho$ and has the different degrees (linear and quadratic) in the proposed equation (20) for transport of heat and (21) for transport of momentum, respectively.

\section{Problem of Input Low-Temperature Data}

To avoid any subjectivity of PCS-estimates one has to use the common approximation scheme at the representation of the selected input (i.e., reference) data on each compound. Two individual coefficients of linear equations (11)-(12) determined for each respective property $\rho_{0}\left(T, P_{0}\right), C_{P}^{0}\left(T, P_{0}\right)$, $c_{s}^{0}\left(T, P_{0}\right)$ from the experimental data [11-19] are reported in Table 1 for $\mathrm{Ar}, \mathrm{N}_{2}, \mathrm{C}_{2} \mathrm{H}_{4}$, and $\mathrm{C}_{2} \mathrm{H}_{6}$ and the set of seven ILs. For the latter the working temperature range [290, $370 \mathrm{~K}]$ of a stable liquid without its upper limit $T_{b}$ (it is unknown, as a rule) was considered. The possible slight curvature of measured data $\rho_{0}\left(T, P_{0}\right)$ often leads to the speculations about the sign of thermal expansivity $\alpha_{P}\left(T, P_{0}\right)$ [25]. For (11) it is fixed and positive, at least, at atmospheric pressure:

$$
\alpha_{P}^{0}=-\frac{1}{\rho}\left(\frac{\partial \rho}{\partial T}\right)_{P_{0}}=\frac{1}{T_{0}-T} .
$$

This simple hyperbola gives, however, the good correspondence with the above experimental data. On the other hand, 
TABLE 1: Linear fit of experimental input data [11-19] by (12)-(13).

\begin{tabular}{|c|c|c|c|c|c|c|c|}
\hline Substance & Reference & $\rho_{0}^{0}, \mathrm{~kg} / \mathrm{m}^{3}$ & $T_{0}, \mathrm{~K}$ & $C_{p_{0}}, \mathrm{~J} / \mathrm{kg} \cdot \mathrm{K}$ & $T_{P}, \mathrm{~K}$ & $c_{s_{0}}, \mathrm{~m} / \mathrm{s}$ & $T_{s}, \mathrm{~K}$ \\
\hline Argon (CXC) & [11] & 1919,23 & 320,27 & 783,57 & 231,83 & 1397,00 & 214,92 \\
\hline Nitrogen & [11] & 1150,07 & 258,92 & 1914,17 & 1190,19 & 1783,33 & 147,59 \\
\hline Ethane & [11] & 754,25 & 663,95 & 2079,02 & 1102,60 & 2628,97 & 372,36 \\
\hline Ethylene & [11] & 790,58 & 600,97 & 1928,57 & 540,00 & 2635,43 & 336,95 \\
\hline$[\mathrm{bmim}]\left[\mathrm{BF}_{4}\right]$ & [12] & 1394,63 & 2170,63 & 1211,79 & 1048,41 & 2223,66 & 997,61 \\
\hline$[\mathrm{bmim}]\left[\mathrm{PF}_{6}\right]$ & {$[14]$} & 1601,25 & 1976,85 & 1082,85 & 1018,31 & 2064,86 & 957,79 \\
\hline$[\mathrm{pmmim}]\left[\mathrm{Tf}_{2} \mathrm{~N}\right]$ & [12] & 1702,36 & 2045,31 & 639,07 & 278,70 & 2458,12 & 889,41 \\
\hline$[\mathrm{EtMePyr}]\left[\mathrm{EtSO}_{4}\right]$ & [19] & 1379,84 & 2235,86 & & & 2494,16 & 1033,08 \\
\hline$[\mathrm{BuEtPyr}]\left[\mathrm{EtSO}_{4}\right]$ & [19] & 1307,73 & 2270,37 & & & 2413,62 & 975,86 \\
\hline$[\mathrm{BuMePyr}]\left[\mathrm{MeSO}_{4}\right]$ & {$[19]$} & 1347,04 & 2226,92 & & & 2519,83 & 973,19 \\
\hline$\left[\mathrm{E}_{3} \mathrm{MNPyr}\right]\left[\mathrm{MeSO}_{4}\right]$ & [19] & 1352,03 & 2244,84 & & & 2663,49 & 1013,29 \\
\hline
\end{tabular}

TABLE 2: Coefficients of first- or second-order polynomial fits for atmospheric isobar $P_{0}$ in different $\Delta T$-intervals.

\begin{tabular}{lccccc}
\hline Compound & $\Delta T$ [exp.], $\mathrm{K}$ & $\rho_{0}^{0}, \mathrm{~g} / \mathrm{cm}^{3}$ & $-\rho_{0}^{\prime} \cdot 10^{+4}, \mathrm{~g} / \mathrm{cm}^{3} \mathrm{~K}$ & $\rho_{0}^{\prime \prime} \cdot 10^{+8}, \mathrm{~g} / \mathrm{cm}^{3} \mathrm{~K}^{2}$ & - \\
\hline$\left[\mathrm{C}_{4} \mathrm{mim}\right]\left[\mathrm{BF}_{4}\right]$ & $295.5-343.9$ & 1.39464 & 6.42562 & - & - \\
{$\left[\mathrm{C}_{4} \mathrm{mim}\right]\left[\mathrm{BF}_{4}\right]$} & $283.2-343.2$ & 1.429 & 7.0 & - & {$[12]$} \\
{$\left[\mathrm{C}_{4} \mathrm{mim}\right]\left[\mathrm{BF}_{4}\right]$} & $283-353$ & 1.41603 & 7.19854 & - & {$[17]$} \\
{$\left[\mathrm{C}_{4} \mathrm{mim}\right]\left[\mathrm{BF}_{4}\right]$} & $314-344$ & 1.40686 & 6.81333 & 65.02034 \\
{$\left[\mathrm{C}_{4} \mathrm{mim}\right]\left[\mathrm{BF}_{4}\right]$} & $298-333$ & 1.47628 & 11.0351 & - & {$[18]$} \\
{$\left[\mathrm{C}_{4} \mathrm{mim}\right]\left[\mathrm{PF}_{6}\right]$} & $298.2-343.2$ & 1.60151 & 8.08889 & - & {$[13]$} \\
{$\left[\mathrm{C}_{4} \mathrm{mim}\right]\left[\mathrm{PF}_{6}\right]$} & $283.2-343.2$ & 1.619 & 8.0 & - & {$[14]$} \\
{$\left[\mathrm{C}_{4} \mathrm{mim}\right]\left[\mathrm{PF}_{6}\right]$} & $313-343$ & 1.60987 & 8.37 & 8.481401 \\
{$\left[\mathrm{C}_{4} \mathrm{mim}\right]\left[\mathrm{PF}_{6}\right]$} & $298-333$ & 1.62070 & & {$[15]$} \\
\hline
\end{tabular}

a variety of $\rho_{0}\left(T, P_{0}\right)$-data for ILs has been measured in the different ranges: $\Delta T=T_{h}-T_{l}$ ( $h$-higher, $l$-lower), with the different levels of accuracy, and some authors [13] have used the quadratic polynomials

$$
\rho_{0}\left(T, P_{0}\right)=\rho_{0}^{0}+\rho_{0}^{\prime} T+\rho_{0}^{\prime \prime} T^{2}
$$

to obtain the best fit. The comparison of such approximation with the different variants of a linear one in (11) reported in Table 2 demonstrates the relatively steady behavior of the "cold" density $\rho_{0}^{0}$ for both popular ILs: $\left[\mathrm{C}_{4} \mathrm{mim}\right]\left[\mathrm{BF}_{4}\right]$ and $\left[\mathrm{C}_{4} \mathrm{mim}\right]\left[\mathrm{PF}_{6}\right]$.

The influence of discussed approximations on the "hot" temperature $T_{0}$ from (11) is more pronounced due to the rather large differences in the negative coefficient $\rho_{0}^{\prime}$ of (26). The coefficients $\rho_{0}^{0}, T_{0}$ reported in Table 3 and calculated without any fit from $\rho_{0}\left(T_{l}\right)$ - and $\rho_{0}\left(T_{h}\right)$-points provide the maximum deviations in the range of $\pm 0.9 \%$.

Since the ultimate goal of developed here methodology is the scaling prediction of transport coefficients, the search for the best fit of input data is not the task of current work.

Most likely such fit cannot affect essentially the predicted values of self-diffusivity, thermal conductivity, and viscosity of liquids if the chosen scaling form of their description is inherently consistent. Nevertheless, to determine the dependences of input data on the scaling variable $x=\rho^{*}$ from (5b) one needs the reliable estimate of excluded low-temperature volume $b_{0}$ (see Table 3 ).
Its value for any ILs can be reasonably estimated [6, 7] just from the long-range extrapolated "cold" volume $v_{0}=$ $1 / \rho_{0}^{0}\left(T \rightarrow 0, P_{0}\right)$. The choice of this work emphasizes that the "cold" volume for the variety of molecular and ionic liquids [7] should be always slightly less than the respective mf-estimate of $b_{c}^{0}$ following from the unified vdW-EOS (the $\mathrm{mf}$-estimate is impossible for ILs):

$$
b_{c}^{0}=\frac{1}{\left(3 \rho_{c}\right)}>b_{0} \approx 1.1 v_{0},
$$

where coefficient 1.1 has $[6,7]$ certain physical meaning.

Indeed, the important, nearly linear correlations of $v_{0}(M)$ for the wide groups of compounds have been revealed as is shown in Figure 2 and represented in Table 3 for 39 compounds.

There are three (apparent to the naked eye) groups of thermodynamically similar, high-molecular-mass substances: (1) heavy normal $n$-alkanes $\mathrm{C}_{n} \mathrm{H}_{2(n+1)}$ with $n \geq 6$; (2) "friable" ILs (mainly, pyrrolidinium- and ammonium-based ones which can be extrapolated to the low-molecular-mass values for Ar, $\mathrm{N}_{2}, \mathrm{Li}$, and $\mathrm{H}_{2} \mathrm{O}$ as well as above $n$-alkanes to the lowmolecular-mass $\mathrm{C}_{2} \mathrm{H}_{6}$ and $\mathrm{C}_{2} \mathrm{H}_{4}$ ); (3) "compact" ILs (only imidazolium-based ones). The terms of friable and compact ILs used here are related exclusively to the interrelation between the "cold" volumes at the equal large molecular masses $M \geq 200 \mathrm{~g} / \mathrm{mol}$. The average percent deviations of 
TABLE 3: Recommended values of excluded molar volume $b_{0}$ determined by the extrapolated linear correlations for low-temperature densities of 39 liquids.

\begin{tabular}{|c|c|c|c|c|c|c|}
\hline Number & Substance & $M, \mathrm{~g} / \mathrm{mol}$ & $v_{0}, \mathrm{~cm}^{3} / \mathrm{mol}$ & $\rho_{0}^{0}, \mathrm{~kg} / \mathrm{m}^{3}$ & $T_{0}, \mathrm{~K}$ & $b_{0}, \mathrm{~cm}^{3} / \mathrm{mol}$ \\
\hline \multicolumn{7}{|c|}{ 1st group (light and heavy $n$-alkanes) } \\
\hline 1 & $\mathrm{C}_{2} \mathrm{H}_{4}$ & 28 & 39,78 & 703,96 & 600,97 & 43,75 \\
\hline 2 & $\mathrm{C}_{2} \mathrm{H}_{6}$ & 30 & 35,42 & 847,05 & 663,95 & 38,96 \\
\hline 3 & $\mathrm{C}_{6} \mathrm{H}_{14}$ & 86 & 92,41 & 930,67 & 1005,47 & 101,65 \\
\hline 4 & $\mathrm{C}_{7} \mathrm{H}_{16}$ & 100 & 105,22 & 950,38 & 1044,95 & 115,74 \\
\hline 5 & $\mathrm{C}_{8} \mathrm{H}_{18}$ & 114 & 120,10 & 949,21 & 1127,99 & 132,11 \\
\hline 6 & $\mathrm{C}_{9} \mathrm{H}_{20}$ & 128 & 134,42 & 952,26 & 1189,77 & 147,86 \\
\hline 7 & $\mathrm{C}_{10} \mathrm{H}_{22}$ & 142 & 148,37 & 957,06 & 1235,91 & 163,21 \\
\hline 8 & $\mathrm{C}_{11} \mathrm{H}_{24}$ & 156 & 162,39 & 960,66 & 1277,25 & 178,63 \\
\hline 9 & $\mathrm{C}_{12} \mathrm{H}_{26}$ & 170 & 176,39 & 963,75 & 1313,68 & 194,03 \\
\hline 10 & $\mathrm{C}_{13} \mathrm{H}_{28}$ & 184 & 189,97 & 968,57 & 1338,26 & 208,97 \\
\hline 11 & $\mathrm{C}_{14} \mathrm{H}_{30}$ & 198 & 203,85 & 971,30 & 1365,63 & 224,24 \\
\hline 12 & $\mathrm{C}_{15} \mathrm{H}_{32}$ & 212 & 217,56 & 974,44 & 1387,10 & 239,32 \\
\hline 13 & $\mathrm{C}_{16} \mathrm{H}_{34}$ & 226 & 231,42 & 976,59 & 1409,23 & 254,56 \\
\hline 14 & $\mathrm{C}_{17} \mathrm{H}_{36}$ & 240 & 245,01 & 979,54 & 1424,79 & 269,51 \\
\hline 15 & $\mathrm{C}_{18} \mathrm{H}_{38}$ & 254 & 258,95 & 980,88 & 1445,12 & 284,85 \\
\hline 16 & $\mathrm{C}_{19} \mathrm{H}_{40}$ & 268 & 272,58 & 983,20 & 1458,76 & 299,84 \\
\hline 17 & $\mathrm{C}_{20} \mathrm{H}_{42}$ & 282 & 286,39 & 984,66 & 1474,05 & 315,03 \\
\hline \multicolumn{7}{|c|}{ 2nd group (friable ILs and light substances) } \\
\hline 1 & $\mathrm{~N}_{2}$ & 28,00 & 24,35 & 1149,90 & 258,92 & 26,79 \\
\hline 2 & $\mathrm{Ar}$ & 39,94 & 20,81 & 1919,27 & 320,27 & 22,89 \\
\hline 3 & 1-Methilimidazole & 82,12 & 63,82 & 1286,74 & 1503,96 & 70,20 \\
\hline 4 & Toluene & 92,14 & 78,88 & 1168,10 & 1140,22 & 86,77 \\
\hline 5 & {$[\mathrm{bmim}][\mathrm{dca}]$} & 205,00 & 167,90 & 1220,96 & 2225.86 & 184,69 \\
\hline 6 & {$[\mathrm{NBuPy}]\left[\mathrm{BF}_{4}\right]$} & 223,02 & 158,71 & 1405,20 & 2195,70 & 174,58 \\
\hline 7 & {$\left[\mathrm{C}_{8} \operatorname{mim}\right]\left[\mathrm{BF}_{4}\right]$} & 282,13 & 219,38 & 1286,03 & 1968,41 & 241,32 \\
\hline 8 & {$\left[\mathrm{C}_{8} \operatorname{mim}\right]\left[\mathrm{PF}_{6}\right]$} & 340,28 & 236,55 & 1438,51 & 2004,15 & 260,21 \\
\hline 9 & {$\left[\mathrm{E}_{3} \mathrm{MN}\right]\left[\mathrm{MeSO}_{4}\right]$} & 343,26 & 253,89 & 1352,00 & 2244,84 & 279,28 \\
\hline 10 & {$[\mathrm{EtMePyr}]\left[\mathrm{EtSO}_{4}\right]$} & 353,25 & 256,01 & 1379,83 & 2235,86 & 281,61 \\
\hline 11 & {$[\mathrm{BuMePyr}]\left[\mathrm{MeSO}_{4}\right]$} & 395,29 & 293,45 & 1347,04 & 2226,92 & 322,80 \\
\hline 12 & {$[\mathrm{BuEtPyr}]\left[\mathrm{EtSO}_{4}\right]$} & 437,34 & 334,43 & 1307,72 & 2270,37 & 367,87 \\
\hline \multicolumn{7}{|c|}{ 3rd group (compact ILs) } \\
\hline 1 & {$[\mathrm{bmim}]\left[\mathrm{BF}_{4}\right]$} & 225,82 & 161,80 & 1395,67 & 2170,63 & 177,98 \\
\hline 2 & {$[\mathrm{bmmim}]\left[\mathrm{BF}_{4}\right]$} & 239,82 & 162,38 & 1476,91 & 1135,72 & 178,62 \\
\hline 3 & {$[\mathrm{bmim}]\left[\mathrm{PF}_{6}\right]$} & 284,00 & 177,36 & 1601,26 & 1976,85 & 195,10 \\
\hline 4 & [bmim] [triflate] & 288,10 & 192,40 & 1497,40 & 2258,09 & 211,64 \\
\hline 5 & {$[\mathrm{bmmim}]\left[\mathrm{PF}_{6}\right]$} & 298,00 & 181,24 & 1644,23 & 1241,47 & 199,36 \\
\hline 6 & {$[\mathrm{emim}]\left[\mathrm{Tf}_{2} \mathrm{~N}\right]$} & 391,00 & 216,92 & 1802,51 & 1903,16 & 238,61 \\
\hline 7 & {$[\mathrm{emmim}]\left[\mathrm{Tf}_{2} \mathrm{~N}\right]$} & 405,00 & 230,37 & 1758,04 & 1936,14 & 253,41 \\
\hline 8 & {$[\mathrm{pmmim}]\left[\mathrm{Tf}_{2} \mathrm{~N}\right]$} & 419,00 & 246,13 & 1702,35 & 2045,31 & 270,74 \\
\hline 9 & {$[\mathrm{bmim}]\left[\mathrm{Tf}_{2} \mathrm{~N}\right]$} & 419,10 & 246,13 & 1702,76 & 1912,71 & 270,74 \\
\hline 10 & [bmim] [methide] & 550,00 & 297,58 & 1848,24 & 1924,63 & 327,34 \\
\hline
\end{tabular}




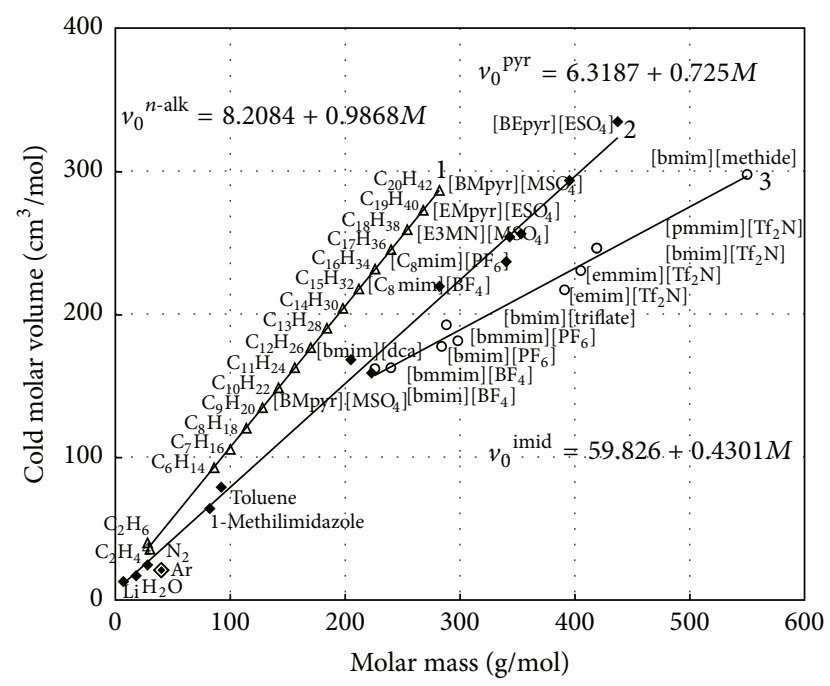

Figure 2: Linear correlations of cold molar volume $v_{0}(M)$ represented for (1)-(3) groups of thermodynamically similar substances (Table 3) (special value for reference argon is shown by $\diamond$ ).

recommended $v_{0}$ values (Table 3 ) from their linear correlations shown in Figure 2 are as follows: for 1st group: 0.22\%, for 2 nd group: $3.96 \%$, and for 3rd group: $2.36 \%$.

All input linear functions of (11)-(12) expressed in terms of $x$,

$$
\begin{aligned}
C_{p} & =C_{p_{0}}\left[1+\frac{T_{0}}{T_{P}}\left(1-\frac{x}{1.1}\right)\right], \\
c_{s} & =c_{s_{0}}\left[1-\frac{T_{0}}{T_{s}}\left(1-\frac{x}{1.1}\right)\right], \\
\bar{u} & =\sqrt{\frac{k_{B} T_{0}}{m_{0}}\left(1-\frac{x}{1.1}\right)},
\end{aligned}
$$

can be now directly used for predictions by (20)-(22). In spite of the dramatic differences between $v_{0}$ values from Table 3 the proposed scaling methodology has to be applicable to all different PCS-types of compounds (Section 5).

\section{Comparison of Predicted Transport Coefficients with Experimental Ones}

5.1. Thermal Conductivity. The spectacular confirmation of universality, which demonstrates the proposed scaling approach, is represented for thermal conductivity in Figure 3. In contrast with the standard PCS approach $[9,10]$ any input values of this quantity itself $\lambda^{0}\left(T^{0}\right)$ taken at the certain fixed temperature $T^{0}$ have not been used. Besides, only lowtemperature data for argon [11] measured within the quite narrow range of temperature $[84,88 \mathrm{~K}]$ are necessary to predict, for example, thermal conductivity of ILs and other compounds in the much wider ranges of temperature shown in Figure 3.

Unfortunately, the experimental data on thermal conductivity (and viscosity) are often scarce and scattered (white

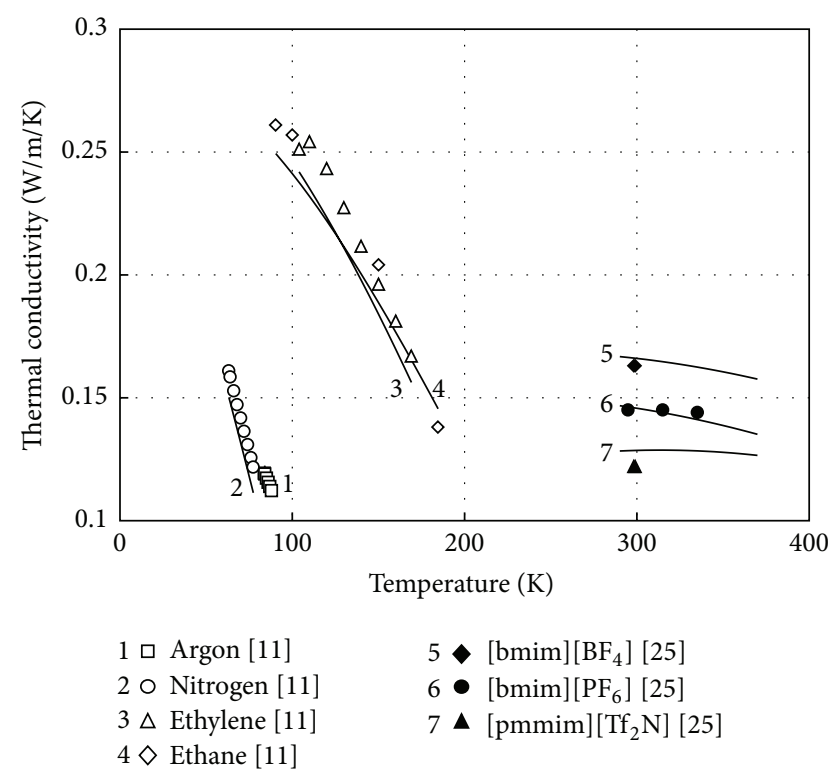

FIgURE 3: Comparison of heat conductivities predicted (curves) by universal (argon-based) scaling function (20) with experimental data (points) at $P_{0} \approx 0,1 \mathrm{MPa}$.

symbols) even for the simple molecular liquids. All measured values for ILs (black symbols) have been taken from the work of Nieto de Castro et al. [25]. I have not found in literature the necessary input data on speed of sound $c_{s}(T)$ for [pmmim] $\left[\mathrm{Tf}_{2} \mathrm{~N}\right]$ and used those (Table 2) for the structurally close $[\mathrm{bmim}]\left[\mathrm{Tf}_{2} \mathrm{~N}\right]$ with the same molecular mass and common anion. The predicted data in Figure 3 are reasonably compatible with the available literature data on $\lambda\left(T, P_{0}\right)$ and the maximum deviations are in the range from -6 to $9 \%$.

It is also important and interesting to calculate the relative percentage contribution of molecular-based mechanism in the overall transport of heat and momentum by equations following from (20) and (21):

$$
\begin{aligned}
& k_{\lambda} \%=\frac{C_{P} \chi^{*} 100}{C_{P} \chi^{*}+2\left(k_{B} / m_{0}\right)\left(c_{s} / \bar{u}\right)}, \\
& l_{\eta} \%=\frac{\nu^{*} 100}{\nu^{*}+\exp \left[0.0192\left(c_{s} / \bar{u}\right)^{2}\right]},
\end{aligned}
$$

where coefficients $A=2$ and $B=0.0192$ are adjusted to the argon data. Such calculations are represented in Table 4 .

One may note that the contribution of molecular mechanism gives roughly one-third in total $\lambda(T)$ for simple molecular substances ( $\left.\mathrm{Ar}, \mathrm{N}_{2}, \mathrm{C}_{2} \mathrm{H}_{4}\right)$ but becomes more than twothirds for ILs ([bmim] $\left[\mathrm{BF}_{4}\right]$, [bmim] $\left[\mathrm{PF}_{6}\right],[\mathrm{pmmim}]\left[\mathrm{Tf}_{2} \mathrm{~N}\right]$ ). The reverse interrelation of contributions is observable for the transport of momentum (see below). It is more than twothirds for simple molecular liquids but becomes relatively small for ILs especially near their melting temperatures. Moreover, the contribution of molecular mechanism in $\eta(T)$ for all pyridinium-based (friable) ILs (not represented in Table 4) is less than $3 \%$ (i.e., negligible) even for the highest temperature of the measured range. Hence, the natural 
TABle 4: Percentage contribution of molecular-based mechanism into the transport of heat $\left(k_{\lambda} \%,(29)\right)$ and momentum $\left(l_{\eta} \%\right.$, $\left.(30)\right)$.

(a)

\begin{tabular}{|c|c|c|c|c|c|c|c|c|}
\hline \multicolumn{3}{|c|}{ Argon } & \multicolumn{3}{|c|}{ Nitrogen } & \multicolumn{3}{|c|}{ Ethylene } \\
\hline$T, \mathrm{~K}$ & $k, \%$ & $l, \%$ & $T, \mathrm{~K}$ & $k, \%$ & $l, \%$ & $T, \mathrm{~K}$ & $k, \%$ & $l, \%$ \\
\hline 83,804 & 26,00 & 73,45 & 63,16 & 33,91 & 72,32 & 104 & 39,43 & 70,28 \\
\hline 84 & 25,96 & 73,46 & 64 & 33,77 & 72,52 & 110 & 39,80 & 71,02 \\
\hline 85 & 25,73 & 73,50 & 66 & 33,38 & 72,94 & 120 & 40,25 & 72,30 \\
\hline 86 & 25,48 & 73,54 & 68 & 32,91 & 73,31 & 130 & 40,46 & 73,40 \\
\hline 87 & 25,22 & 73,57 & 70 & 32,37 & 73,63 & 140 & 40,43 & 74,29 \\
\hline \multirow[t]{4}{*}{88} & 24,95 & 73,60 & 72 & 31,73 & 73,90 & 150 & 40,11 & 74,97 \\
\hline & & & 74 & 30,99 & 74,13 & 160 & 39,45 & 75,45 \\
\hline & & & 76 & 30,13 & 74,31 & 169,13 & 38,47 & 75,74 \\
\hline & & & 77,35 & 29,48 & 74,42 & & & \\
\hline
\end{tabular}

(b)

\begin{tabular}{|c|c|c|c|c|c|c|c|c|}
\hline \multicolumn{3}{|c|}{$[\mathrm{bmim}]\left[\mathrm{BF}_{4}\right]$} & \multicolumn{3}{|c|}{$[\mathrm{bmim}]\left[\mathrm{PF}_{6}\right]$} & \multicolumn{3}{|c|}{$[\mathrm{pmmim}]\left[\mathrm{Tf}_{2} \mathrm{~N}\right]$} \\
\hline$T, \mathrm{~K}$ & $k, \%$ & $l, \%$ & $T, \mathrm{~K}$ & $k, \%$ & $l, \%$ & $T, \mathrm{~K}$ & $k, \%$ & $l, \%$ \\
\hline 290 & 71,52 & 20,87 & 290 & 72,49 & 14,37 & 290 & 77,97 & 9,95 \\
\hline 300 & 71,90 & 23,80 & 300 & 72,81 & 17,04 & 300 & 78,50 & 12,57 \\
\hline 310 & 72,25 & 26,82 & 310 & 73,12 & 19,89 & 310 & 79,00 & 15,52 \\
\hline 320 & 72,59 & 29,86 & 320 & 73,40 & 22,85 & 320 & 79,48 & 18,74 \\
\hline 330 & 72,91 & 32,89 & 330 & 73,67 & 25,88 & 330 & 79,93 & 22,18 \\
\hline 340 & 73,21 & 35,86 & 340 & 73,91 & 28,93 & 340 & 80,36 & 25,77 \\
\hline 350 & 73,50 & 38,75 & 350 & 74,14 & 31,96 & 350 & 80,78 & 29,43 \\
\hline 360 & 73,77 & 41,53 & 360 & 74,35 & 34,94 & 360 & 81,17 & 33,09 \\
\hline 370 & 74,03 & 44,19 & 370 & 74,54 & 37,83 & 370 & 81,54 & 36,70 \\
\hline
\end{tabular}

conclusion is that the transport of momentum in such ILs has the dominantly wave mechanism.

5.2. Viscosity. Taking into account the results of Table 4 it is especially interesting to discuss the scaling prediction of $\eta(T)$, namely, for the pyridinium-based ILs (Figures 5 and 6) and to compare it with the results for simple molecular liquids (Figure 4).

Again the spectacular predictive abilities of the scaling approach as well as its universality are evident. All measured $\eta(T)$-data represented by black symbols in Figures 5 and 6 for the pairs of ILs with the common anions $\left(\left[\mathrm{EtSO}_{4}\right]\right.$ and $\left[\mathrm{MeSO}_{4}\right]$, resp.) have been taken from the work of Gonzále et al. [19]. This work contains also the necessary input data on density $\rho_{0}\left(T, P_{0}\right)$ and speed of sound $c_{s}\left(T, P_{0}\right)$. Again the reasonable $(<30 \%)$ overall level of accuracy was demonstrated, though for some ILs $\left([\mathrm{EtMePyr}]\left[\mathrm{MeSO}_{4}\right]\right)$ and $\left([\mathrm{EtMePyr}]\left[\mathrm{EtSO}_{4}\right]\right)$ the deviations from experiment [19] were large and systematic while for the others $\left([\mathrm{BuEtPyr}]\left[\mathrm{EtSO}_{4}\right]\right.$ and $\left.[\mathrm{BuMePyr}]\left[\mathrm{MeSO}_{4}\right]\right)$ were close to the experimental uncertainties.

At the same time, our attempt to predict the viscosity for two compact imidazolium-based ILs ([bmim] $\left[\mathrm{BF}_{4}\right]$ and [bmim $\left.]\left[\mathrm{PF}_{6}\right]\right)$ with the common cation was not so successful. The use of input data on density $\rho\left(T, P_{0}\right)$ and speed of sound $c_{s}\left(T, P_{0}\right)$ reported in the work [13] predicts by (21)

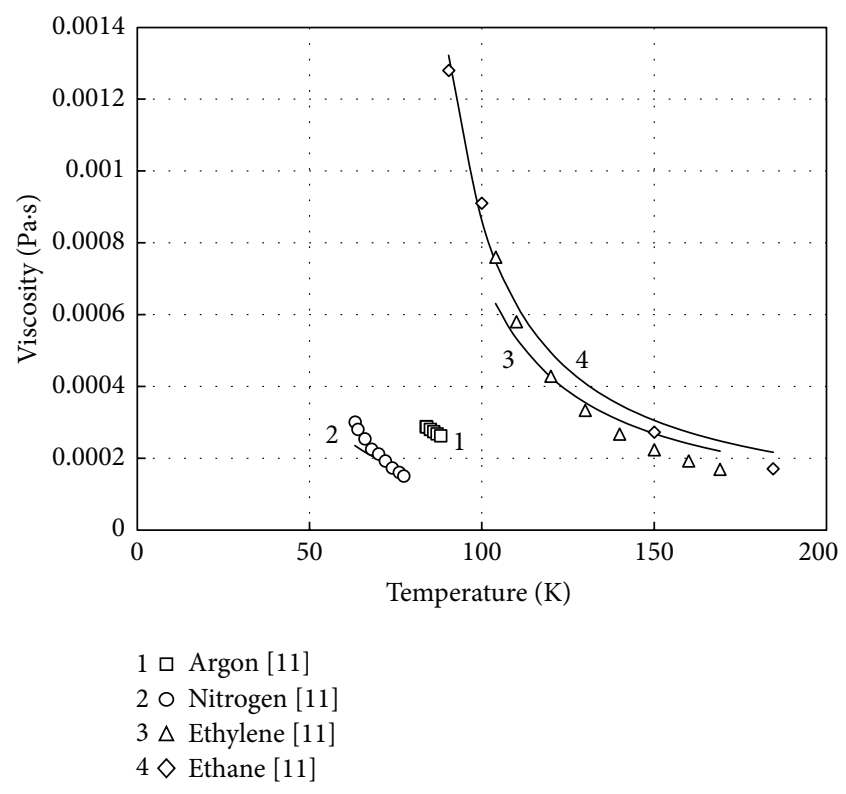

FIGURE 4: Comparison of viscosities for molecular liquids predicted (curves) by universal (argon-based) scaling function (21) with experimental data (points) at $P_{0} \approx 0,1 \mathrm{MPa}$.

the significantly underestimated quantities of $\eta\left(T, P_{0}\right)$ (located between the limits 0,006 and $0,001 \mathrm{~Pa} \cdot \mathrm{s}$ ). Such 


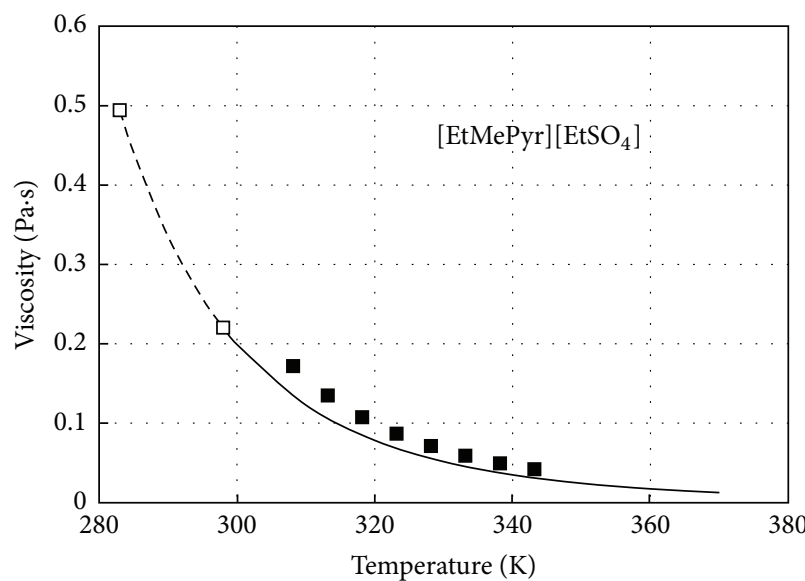

(a)

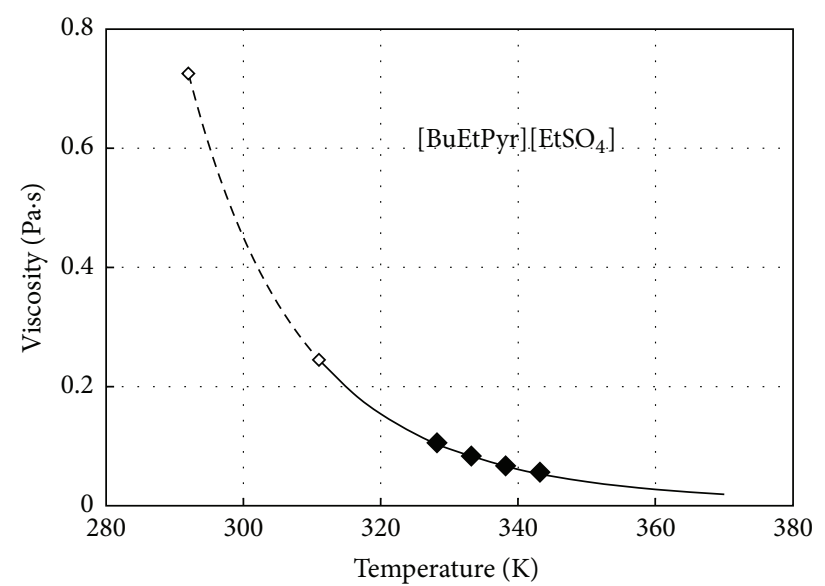

(b)

FIGURE 5: Experimental [19] (points) and predicted (curves) by scaling (argon-based) universal equation (21) viscosities for pyridinium-based ILs with the common anion $\left[\mathrm{EtSO}_{4}\right]$. The extrapolated $\eta(T)$ values in the metastable range between melting $T_{m}$ and freezing $T_{f}$ temperatures are shown by dashed curves.

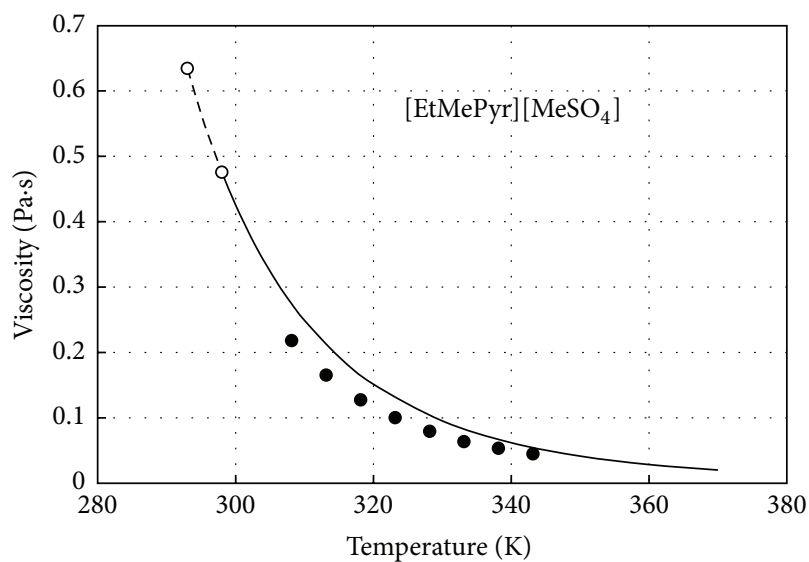

(a)

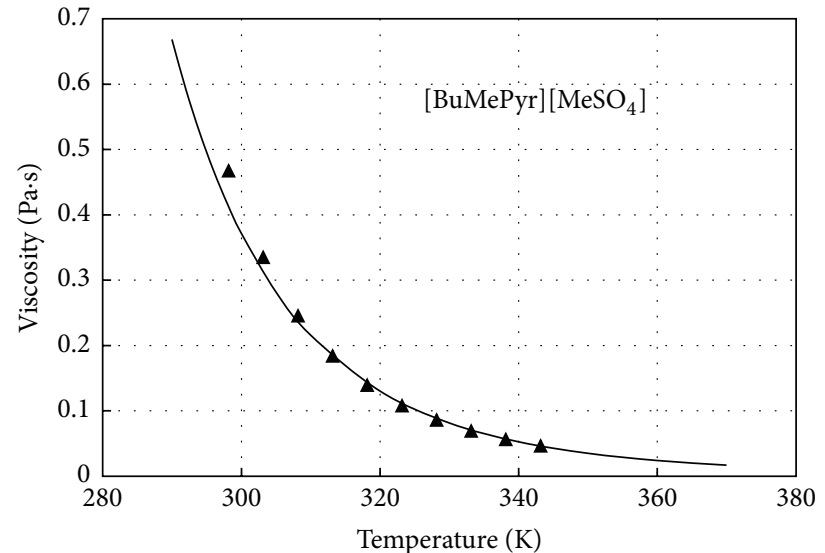

(b)

FIGURE 6: Experimental [19] (points) and predicted (curves) by scaling (argon-based) universal equation (21) viscosities for pyridinium-based ILs with the common anion $\left[\mathrm{MeSO}_{4}\right]$. The extrapolated $\eta(T)$ values in the metastable range between melting $T_{m}$ and freezing $T_{f}$ temperatures are shown by dashed curves (both of the above temperatures are unobservable experimentally [19] for $\left[\mathrm{BuMePyr}^{\mathrm{B}}\left[\mathrm{MeSO}_{4}\right]\right.$ ).

predicted values are larger than those for molecular liquids (located (see Figure 4) for $\mathrm{C}_{2} \mathrm{H}_{4}$ and $\mathrm{C}_{2} \mathrm{H}_{6}$ between the limits of 0,0015 and 0,0002 Pa.s and for $\mathrm{Ar}$ and $\mathrm{N}_{2}$ between the limits of 0,0003 and $0,00015 \mathrm{~Pa} \cdot \mathrm{s}$ ) but much lower than ones reported by different authors for $[\mathrm{bmim}]\left[\mathrm{PF}_{6}\right]$ (e.g., $0,173 ; 0,2179 ; 0,272 ; 0,450 \mathrm{~Pa} \cdot \mathrm{s}[26-28])$. Of course, the accuracy of the above scattered experimental data must be improved because here the presumable sharp jump between the average viscosities of friable and compact ILs may be the illuminating factor at the choice of IL for practical usage. High sensitivity of results to the input $c_{s}(T)$ value has been confirmed, namely, for the viscosity (21), while the thermal conductivity (20) remains relatively insensitive to its value.

5.3. Prandtl's Number. The remarkable predictive abilities of the scaling approach are again confirmed by Figure 7(a) for molecular liquids and, partially, for the imidazolium-based ILs by Figure 7(b). Taking into account the relative failure of proposed methodology at the prediction of viscosity for [bmim $]\left[\mathrm{BF}_{4}\right]$ and $[\mathrm{bmim}]\left[\mathrm{PF}_{6}\right]$, it is interesting to test its ratio $(\overline{\operatorname{Pr}})$ at the respective, reasonably predicted $\lambda(T)$ value for them as is shown in Figure 3. The result of such test is rather unwonted. The scaling approach predicts the absolutely realistic $\overline{\mathrm{Pr}}$ values for both $[\mathrm{bmim}]\left[\mathrm{BF}_{4}\right]$ and $[\mathrm{bmim}]\left[\mathrm{PF}_{6}\right]$ (compatible with that (experimental) for $[\mathrm{pmmim}]\left[\mathrm{Tf}_{2} \mathrm{~N}\right]$ ) shown in Figure 7(b). The only reason of such observation follows from the definition of $\overline{\mathrm{Pr}}$-number by (22). To compensate the presumably underestimated dynamic viscosity $\eta$ one needs the significantly overestimated $C_{P}$ values for the prediction of realistic $\overline{\mathrm{Pr}}$. This trend is confirmed, partially, in the measurements of isobaric heat capacity of ILs by different authors [29]. The comparison of $\overline{\operatorname{Pr}}$ for molecular 


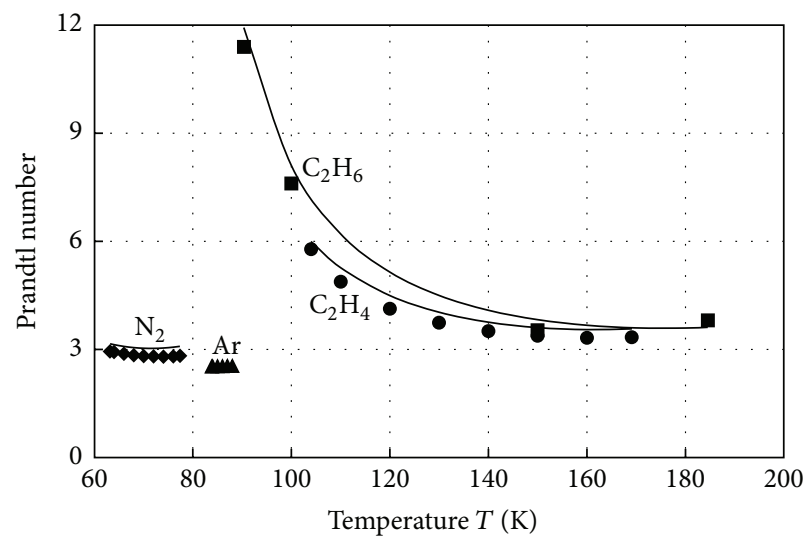

(a)

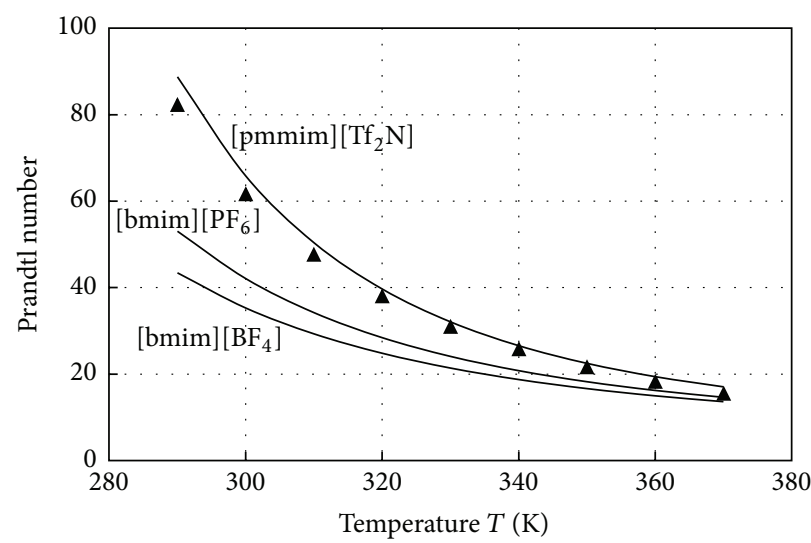

(b)

Figure 7: Experimental (points) and predicted (curves) by the universal argon-based scaling function (22) Prandtl's numbers for the wide range of temperatures in the molecular (a) and ionic (b) liquids at $P=0,1 \mathrm{MPa}$.

liquids (Figure $7(\mathrm{a})$ ) with that for ILs leads to the simple practical conclusion. The latter is preferable, in total, as the thermal storage media while the imidazolium-based ILs can be, additionally, useful as the potential heat-transfer liquids too.

\section{Conclusions}

The predictive abilities and universality of the proposed scaling model of low-temperature transport coefficients are obvious. This model is testable by the MD-simulations based on the thermodynamically predicted LJ-parameters $\sigma_{0}$ and $\varepsilon(T)$ here. The derived exact form of EOS for LJ-liquid leads to the potential possibility to construct the crossover formalism connecting critical $\left(T_{c}\right)$ and normal boiling $\left(T_{b}\right)$ regions by the FT-model's concepts and results.

\section{Conflict of Interests}

The author declares that there is no conflict of interests regarding the publication of this paper.

\section{References}

[1] W. G. Hoover, G. Stell, E. Goldmark, and G. D. Degani, "Generalized van der Waals equation of state," The Journal of Chemical Physics, vol. 63, pp. 5434-5438, 1975.

[2] V. B. Rogankov and V. I. Levchenko, "Global asymmetry of fluids and local singularity in the diameter of the coexistence curve," Physical Review E, vol. 87, Article ID 052141, 2013.

[3] V. B. Rogankov, "Fluctuational-thermodynamic interpretation of small angle X-ray scattering experiments in supercritical fluids," Fluid Phase Equilibria, vol. 383, pp. 115-125, 2014.

[4] V. B. Rogankov and L. Z. Boshkov, "Gibbs solution of the van der Waals-Maxwell problem and universality of the liquid-gas coexistence curve," Physical Chemistry Chemical Physics, vol. 4, no. 6, pp. 873-878, 2002.

[5] V. A. Mazur and V. B. Rogankov, "A novel concept of symmetry in the model of fluctuational thermodynamics," Journal of Molecular Liquids, vol. 105, no. 2-3, pp. 165-177, 2003.
[6] V. B. Rogankov, "Asymmetry of heterophase fluctuations in nucleation theory," in Nucleation Theory and Applications, J. W. P. Schmelzer, G. Röpke, and V. Priezshev, Eds., chapter 22, pp. 227-241, Joint Institute for Nuclear Research, Dubna, Russia, 2011.

[7] V. B. Rogankov, "Equation of state for ionic liquids," High Temperature, vol. 47, no. 5, pp. 656-663, 2009.

[8] J. K. Johnson, J. A. Zollweg, and K. E. Gubbins, “The LennardJones equation of state revisited," Molecular Physics, vol. 78, no. 3, pp. 591-618, 1993.

[9] L. P. Filippov, Methods of Calculation and Prediction for Thermophysical Properties, Moscow University Publications, Moscow, Russia, 1988.

[10] I. I. Novikov, "Izbrannye trudy," in Selected Works, Fizmathlit, Ed., Fizmathlit, Moscow, Russia, 2007 (Russian).

[11] N. B. Vargaftik, Handbook of Thermophysical Properties for Gases and Liquids, Nauka, Moscow, Russia, 1972 (Russian).

[12] C. P. Fredlake, J. M. Crosthwaite, D. G. Hert, S. N. V. K. Aki, and J. F. Brennecke, "Thermophysical properties of imidazoliumbased ionic liquids," Journal of Chemical and Engineering Data, vol. 49, no. 4, pp. 954-964, 2004.

[13] R. G. de Azevedo, J. M. S. S. Esperança, V. NajdanovicVisak et al., "Thermophysical and thermodynamic properties of 1-butyl-3-methylimidazolium tetrafluoroborate and 1-butyl3-methylimidazoliuin hexafluorophosphate over an extended pressure range," Journal of Chemical and Engineering Data, vol. 50, no. 3, pp. 997-1008, 2005.

[14] Z. Gu and J. F. Brennecke, "Volume expansivities and isothermal compressibilities of imidazolium and pyridinium-based ionic liquids," Journal of Chemical \& Engineering Data, vol. 47, no. 2, pp. 339-345, 2002.

[15] A. Kumar, "Estimates of internal pressure and molar refraction of imidazolium based ionic liquids as a function of temperature," Journal of Solution Chemistry, vol. 37, no. 2, pp. 203-214, 2008.

[16] H. Machida, Y. Sato, and R. L. Smith Jr., "Pressure-volume-temperature $(\mathrm{PVT})$ measurements of ionic liquids $\left(\left[\mathrm{bmim}^{+}\right]\left[\mathrm{PF}_{6}^{-}\right]\right.$, $\left.\left[\mathrm{bmim}^{+}\right]\left[\mathrm{BF}_{4}^{-}\right], \quad\left[\mathrm{bmim}^{+}\right]\left[\mathrm{OcSO}_{4}^{-}\right]\right)$and analysis with the Sanchez-Lacombe equation of state," Fluid Phase Equilibria, vol. 264, no. 1-2, pp. 147-155, 2008. 
[17] D. Matkowska and T. Hofman, "High-pressure volumetric properties of ionic liquids: 1-butyl-3-methylimidazolium tetrafluoroborate, $\left[\mathrm{C}_{4} \mathrm{mim}\right]\left[\mathrm{BF}_{4}\right]$, 1-butyl-3-methylimidazolium methylsulfate $\left[\mathrm{C}_{4} \mathrm{mim}\right]\left[\mathrm{MeSO}_{4}\right]$ and 1-ethyl-3-methylimidazolium ethylsulfate, $\left[\mathrm{C}_{2} \mathrm{mim}\right]\left[\mathrm{EtSO}_{4}\right]$," Journal of Molecular Liquids, vol. 165, pp. 161-170, 2012.

[18] L. P. N. Rebelo, J. N. C. Lopes, J. M. S. S. Esperança, and E. Filipe, "On the critical temperature, normal boiling point, and vapor pressure of ionic liquids," Journal of Physical Chemistry B, vol. 109, no. 13, pp. 6040-6043, 2005.

[19] B. Gonzále, E. Gómez, Á. Domínguez, M. Vilass, and E. Tojos, "Physicochemical characterization of new sulfate ionic liquids," Journal of Chemical \& Engineering Data, vol. 56, no. 1, pp. 14-20, 2011.

[20] G. Marc and W. G. McMillan, “The virial theorem," Advances in Chemical Physics, vol. 58, pp. 209-361, 1985.

[21] V. P. Maslov, "Thermodynamic equation of state with three defining constants," Mathematical Notes, vol. 87, pp. 723-731, 2010.

[22] V. P. Maslov, "Thermodynamic equations of state with three defining constants," Mathematical Notes, vol. 87, no. 5-6, pp. 728-737, 2010.

[23] R. Balesku, Equilibrium and Nonequilibrium Statistical Mechanics, Wiley-Interscience, New York, NY, USA, 1977.

[24] Y. B. Zeldovich and U. P. Raizer, Physics of Shock Waves and High-Temperature Hydrodynamic Phenomena, Nauka, Fizmatgiz, Moscow, Russia, 1966.

[25] C. A. Nieto de Castro, M. J. V. Lourenço, A. P. C. Ribeiro et al., "Thermal properties of ionic liquids and IoNanoFluids of imidazolium and pyrrolidinium liquids," Journal of Chemical and Engineering Data, vol. 55, no. 2, pp. 653-661, 2010.

[26] J. Zhu, J. Chen, C. Li, and W. Fei, "Viscosities and interfacial properties of 1-methyl-3-butylimidazolium hexafluorophosphate and 1-isobutenyl-3-methylimidazolium tetrafluoroborate ionic liquids," Journal of Chemical \& Engineering Data, vol. 52, no. 3, pp. 812-816, 2007.

[27] O. O. Okoturo and T. J. Vander Noot, “Temperature dependence of viscosity for room temperature ionic liquids," Journal of Electroanalytical Chemistry, vol. 568, no. 1-2, pp. 167-181, 2004.

[28] K. R. Harris, L. A. Woolf, and M. Kanakubo, “Temperature and pressure dependence of the viscosity of the ionic liquid 1-butyl-3-methylimidazolium hexafluorophosphate," Journal of Chemical and Engineering Data, vol. 50, no. 5, pp. 1777-1782, 2005.

[29] B. Wu, R. G. Reddy, and R. D. Rogers, "Novel ionic liquid thermal storage for solar thermal electric power systems," in Proceedings of the Solar Forum Conference, Washington, DC, USA, April 2001. 

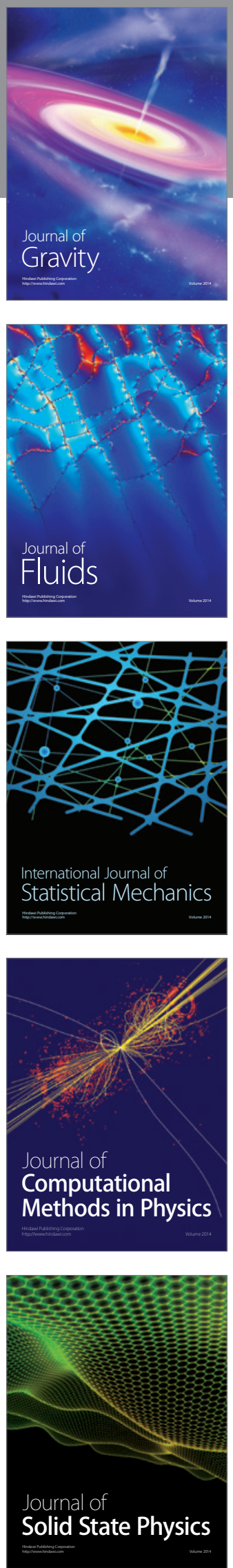

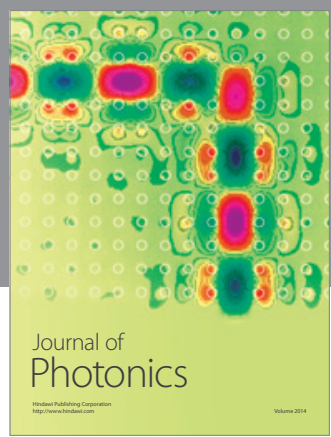

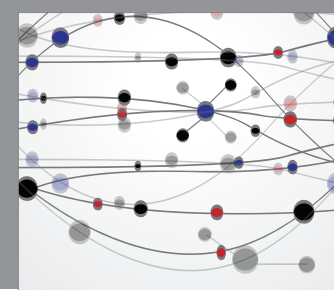

The Scientific World Journal

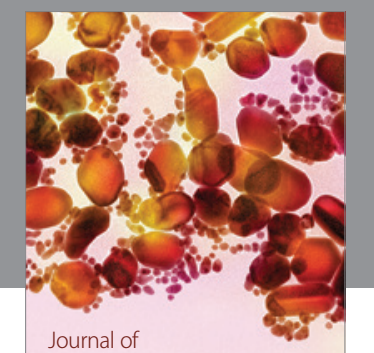

Soft Matter
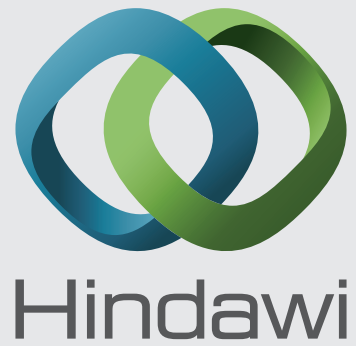

Submit your manuscripts at

http://www.hindawi.com
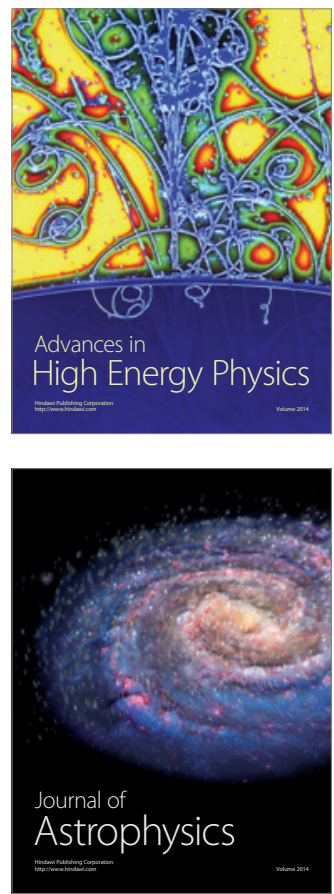
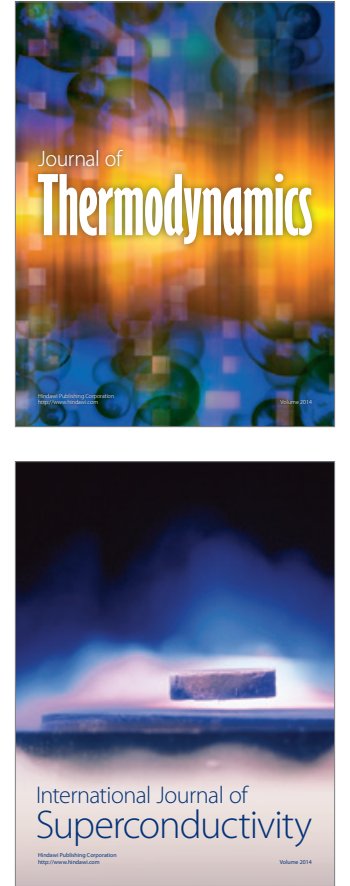
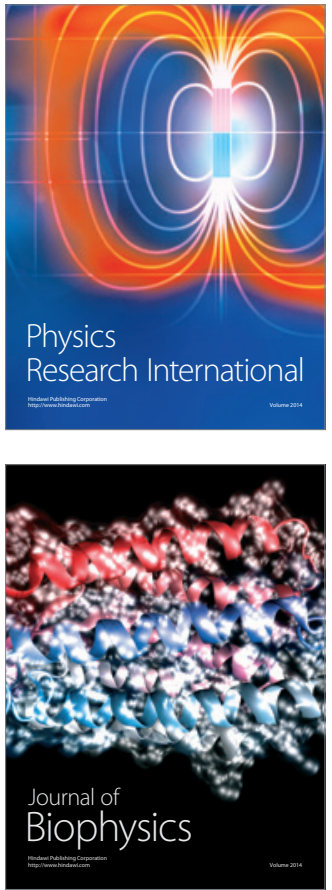
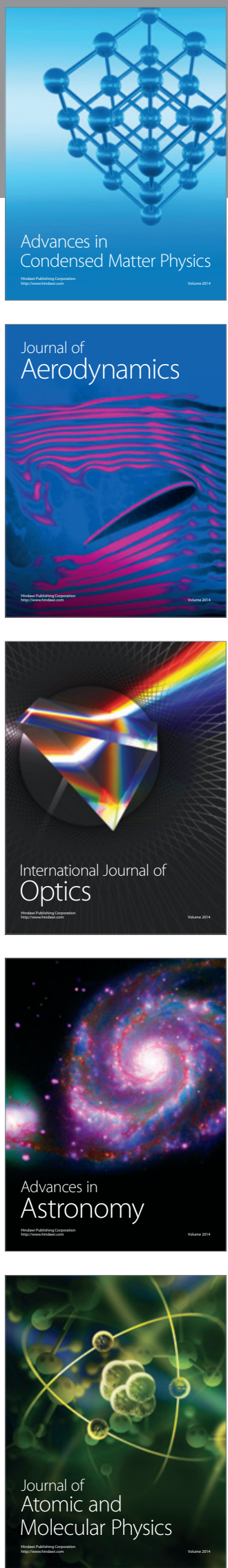